Opinion

\title{
Scientific writing: a push forward against delaying
}

Volume 2 Issue 2 - 2015

\section{Opinion}

Scientific writing is of vital importance for all scientific researchers. It is absolutely a very useful mean for effective communication among scientific world and for knowledge and experiences exchange, which also could conferee the writer recognition worldwide. ${ }^{1}$ Moreover, this could also help the researcher to apply for grants and findings for their research. ${ }^{2}$ It is consensus that experiment findings have to be written, then published, otherwise they would not be known by other members in scientific community.

The researchers usually build their work on previously published papers related to their research topic, which would be extremely difficult to refer to without reading those published papers, hence the importance of publishing research work results. The most necessary skill to fulfill this goal is scientific writing, which should be highly accurate, brief and clear. Not only original research papers are important for science advancement, but also are review papers, editorials, opinions, and other forms of publication.

Writing a scientific paper, whatever its type, requires a good command of language, and more precisely an accurate scientific language. However, this obstacle does not resemble to be the most challenging difficulty, since we can notice that a huge number of scientist writers, for instance, in English, are not native speakers, however, their scientific English writing is not less skilled than those whose mother language is English.

Scientific writers, particularly beginners, would have other struggles in writing that I would like to put a spotlight on, and, with suggesting certain hopefully useful ideas to overcome them. Scientific research experiments are usually laborious, especially for student who are also under the pressure of graduation requirements, problems of arranging their schedule depending on many factors, such as delays in purchased items arrival, being busy all the time with laboratory work, and becoming bored from writing technical words that should be highly accurate and far from the beautiful literature language of novels and poems.

In this regard, I suggest for the writer of a scientific paper some simple and practical solutions.

i. The variation in the background of the paper, or letters color while writing a manuscript instead of writing routinely in black on white, would be a useful way; the writer could choose from a rich palette of colors, which might make a helpful change from the ordinary writing habit.

ii. Changing the writing letters style, size, or writing in italic and other characteristics from time to time, would also help greatly.

iii. I suggest, further, changing the place for writing periodically. The writer could also change the surrounding air freshener perfume, or rearrange the gadgets on their desk in order to ameliorate writing ambience.

\author{
Besma Boubertakh \\ Key Laboratory of Animal Models and Human Disease \\ Mechanisms of Chinese Academy of Sciences \& Yunnan Province, \\ Kunming Institute of Zoology, China
}

Correspondence: Besma Boubertakh, Key Laboratory of Animal Models and Human Disease Mechanisms of Chinese Academy of Sciences \& Yunnan Province, Kunming Institute of Zoology, Kunming, Yunnan 650223, University of Chinese Academy of Sciences, Beijing 10049, China, Tel 8620000000000 Email www.boubertakhbesma@outlook.com

Received: October 30, 2014 | Published: January 27, 2015

iv. Moreover, I think that scientific papers would be clearer if they contain photos from the experiment processes, and not only the experiment findings curves, bar charts, tables, and so on. This could help to make the scientific writing a more enjoyable practice.

v. I would further suggest that a scientific paper would include a footnote about a proverb or an advice for experiment practice which may help other scientists, and add a nice touch to the published paper.

vi. Selecting some photos presenting the importance of the problem written about and choosing them as computer desktop background, or sticking them near writing environment should be also an encouraging way for the writer, to remind them that this paper would help to resolve a problem, and may help people suffering from a disease, for instance, and which could remind the writer that what they are doing has a Nobel aim, which would be highly pushing forward towards more enthusiasm for scientific writing.

\section{Acknowledgments}

None.

\section{Conflicts of interest}

Author declares there are no conflicts of interest.

\section{Funding}

None. 